\title{
Investigation of the Effect of Tumor Location in Patients with Stage III Colon Cancer Receiving Adjuvant Oxaliplatine-Based Adjuvant Chemotherapy
}

\author{
Semiha URVAY ${ }^{1}$, Hacer DEMIR ${ }^{2}$, Ali GOKYER ${ }^{3}$, Ilhan HACIBEKIROGLU ${ }^{4}$, \\ Ahmet KUCUKARDA ${ }^{3}$, Emre CAKIR ${ }^{4}$, Ismail BEYPINAR ${ }^{5}$, Necla DEMIR ${ }^{6}$, \\ Burak CIVELEK ${ }^{1}$, Ersin OZASLAN ${ }^{1}$ \\ ${ }^{1}$ Acibadem Kayseri Hospital, Department of Medical Oncology, Kayseri \\ ${ }^{2}$ Afyonkarahisar Health Science University, Department Internal Medicine and Medical Oncology, Afyonkarahisar \\ ${ }^{3}$ Trakya University Faculty of Medicine, Department of Medical Oncology, Edirne \\ ${ }^{4}$ Sakarya University Training and Research Hospital, Department Internal Medicine and Medical Oncology, Sakarya \\ ${ }^{5}$ Eskişehir City Hospital, Department of Medical Oncology, Eskişehir \\ ${ }^{6}$ Medicana Hospital, Department of Medical Oncology, Sivas, TURKEY
}

\begin{abstract}
Left-sided ( $\mathrm{LCC}$ ) and right-sided (RCC) colon cancers have different prognostic and predictive features in metastatic colon cancers, however there is insufficent data about tumor location in stage III disease. The aim of this study is to investigate the effect of tumor location on prognosis in patients with stage III colon cancer. From 2006 to 2012, medical records of 215 patients who underwent primary surgery and received adjuvant oxaliplatin based chemotherapy at 5 referral centers were collected, retrospectively. Diseasefree survival (DFS) and overall survival were analysed using Kaplan-Meier and log-rank tests, and prognostic facrtors were identified by Cox regression methods. Clinicopathological characteristics of patients were similar between patients with right-and left-sided colon cancers. The 3-year DFS rate was similar ( $88 \%$ vs $78 \%, p=0.07$ ) but the RCC was significantly associated with a shorter 3-year OS than LCC (76\% vs $87 \%, p=0.03)$. The 3-year median OS was 125.8 months for all patients groups, $92.2( \pm 5.81)$ months for the RCCs and $132.2( \pm 5.52)$ months for the LCCs $(p=0.037)$. Multivariate analysis showed that stage $(H R: 0.32, p=0.042$ for OS) and venous invasion (HR: $0.28, p=0.002$ for OS) were the independent prognostic factors. Although there was no DFS difference between RCCs and LCCs, poorer survival of RCC indicated that the prognosis of RCC worsened after transitioning to the metastatic stage. Tumor location may be a prognostic factor in metastatic colon cancer but not in stage III disase.
\end{abstract}

Keywords: Colon cancer, Stage III, Left-sided colon cancers, Right-sided colon cancers

\section{INTRODUCTION}

Colorectal cancer (CRC) accounts for $10 \%$ of all tumour types worldwide and is the third most common cancer in men and the second in women. ${ }^{1}$ Most newly diagnosed patients present with locoregional disease and can potantially be cured with a combination of chemotherapy and surgery. ${ }^{2}$ Today, colon is not considered as a single entity, it is divided into two parts as right colon and left colon. ${ }^{3,4}$ Cancer originating from cecum, ascending colon, hepatic flexura and transverse colon is defined as right-sided colon cancer (RCC); cancer from splenic flexura, descending colon and sigmoid colon and rectum is defined as left-sided colon cancer (LCC). ${ }^{5,6}$ Increasing evidence demonstrated that cancers originating from different sides of the colon shows different characteristics such as molecular alterations, epidemiological incidence, physiological characteristics and different survival outcomes. ${ }^{1,-9}$ 
Compared to LCC, RCC is more frequently poor differentiated and presents with locally advanced tumors that have several specific molecular features including a high level 5'C-phosphate-G-3' (CpG) island methylator phenotype (CIMP), BRAF mutations, microsatellite instability (MSI) and worse survival outcomes. ${ }^{7,810}$ There are many studies reporting that the oncological outcomes of colon cancer differ according to the location of the tumor. Most studies have reported worse oncologic outcomes in patients with RCC compared with patients with LCC. ${ }^{11-15}$

Despite these different characteristics, 6-months adjuvant chemotherapy with oxaliplatin and fluoropyrimidines is standard of care in patients with operated stage III colon cancer regardless of the tumor location. ${ }^{16-22}$ Indeed, nearly $30 \%$ of patients can not complete the full planned course of adjuvant chemotherapy due to poor tolerance and therapeutic toxicity ${ }^{17,21,23}$ and $25 \%$ to $30 \%$ of stage III colon cancer patients develop distant metastasis despite curative treatment. ${ }^{24,25}$ Therefore, the management of stage III colon cancer is still challenging and better insight into the prognostic factors are important for personalization of adjuvant chemotherapy. Grothey et al. showed that stage III operated colon cancer patients with T4 or N2 had a very similar, poor prognosis than other groups and needs longer adjuvant treatment duration. ${ }^{26}$ However, this study did not mention the effect of tumor location. Peng et al. reported that RCC patients with stage III colon cancer had a worse prognostic outcome and a full course of adjuvant chemotherapy should be offered to patients with RCC, but not to patients with LCC. ${ }^{27}$ Because of the structural and prognostic differences between the left and right colon, it can be thought that the efficacy of oxaliplatin-containing adjuvant chemotherapy is not only influenced by tumor stage, but also by tumor location.

In these study, we aimed to examine the survival outcome of operated stage III colon cancers patients by tumor location and the importance of tumor location in order to optimize the adjuvan chemotherapy duration of these patients.

\section{PATIENTS AND METHODS}

\section{Patients}

This was a retrospective study conducted at five
Turkish institutes and approved by the ethics committee of Acıbadem Healthcare Organizations Medical Research Ethics Committee (No 2020-02/37).

215 consecutive patients diagnosed with stage III colon cancer and underwent tumor resection followed by adjuvant chemotherapy from June 2006 to December 2016 were included in the study. The patients with rectal cancer were excluded. The patients medical records were reviewed to obtain data on clinic-pathologic variables. The pathological tumor-node-metastasis (TNM) classification was defined acccording to the criteria of the American Joint Commision on Cancer (AJCC) 8th edition. ${ }^{28}$

Tumors distal to the splenic flexura were classified as left colon, and tumors proximal to splenic flexura were classified as right colon. The reference duration of 6 months was chosen in accordance with pivotal trials in which the efficacy of the duration had been established. The patients who completed their treatment for 6 months were defined as the full treatment group, and those whose treatment was less than 6 months were defined as the short treatment group. The college of American Pathologist recommend examination of a minimum of 12 lymph nodes to accurately stage colon cancers, ${ }^{29}$ therefore the 12 is used as a cut off value for lymph node dissection.

Since T4 and N2 stages were shown to be associated with poor prognosis in operated stage 3 colon cancer, the patients were classified as $\mathrm{N} 2$ versus $\mathrm{N} 1$ and $\mathrm{T} 4$ versus $\mathrm{T} 1-3$.

\section{Treatment}

All patients received modified FOLFOX [oxaliplatin $\left(85 \mathrm{mg} / \mathrm{m}^{2}\right.$ intravenously over $2 \mathrm{~h}$ on day 1$)$ plus $\mathrm{LV}\left(400 \mathrm{mg} / \mathrm{m}^{2}\right.$ intravenously over $2 \mathrm{~h}$ on day 1$)$ and 5 -fluorouracil (5-FU) $\left(400 \mathrm{mg} / \mathrm{m}^{2}\right.$ bolus on day 1, followed by infusion of $2400 \mathrm{mg} / \mathrm{m}^{2}$ over $46 \mathrm{~h}$ )] or XELOX (capecitabine $1000 \mathrm{mg} / \mathrm{m}^{2}$ BID po x14 days plus oxaliplatin $130 \mathrm{mg} / \mathrm{m}^{2}$, every 21 days for 8 cycles) in adjuvant therapy.

\section{Statistical Analysis}

All of the data were analyzed using IBM SPSS statistics software, version 21.0. The correlations between clinicopathological variables and tumor lo- 
cation were assessed using chi-squared test or Fisher's exact test. The 3-year DFS and OS rates were calculated with the Kaplan-Meier method, and the differences were compared with the log-rank test. Overall survival (OS) was defined as the interval (in months) from the date of surgery until death from any cause or the last follow up, whereas disease free survival (DFS) was defined as the interval (in months) from date of surgery to disease recurrence, death, or the last follow-up. A Cox proportional hazards model was used to calculate hazard ratios and 95\% confidence intervals for both univariate and multivariate analyses. P-values $<0.05$ was considered significant.

\section{RESULTS}

\section{Patient characteristics}

The baseline characteristics of the patients are shown in Table 1. Their median age was 61 (range, 23-81years). 122 patients (56.7\%) were men and 92 patients (43.35) were women. $9(4.2 \%)$ patients were diagnosed with stage IIIA colon cancer, 161 (74.8\%) with stage IIIB colon cancer, and $45(21 \%)$ with stage IIIC colon cancer. 139 (64.6\%) patients had LCC while 76 (35.4\%) patients had RCC. The median number of resected lymph nodes and metastatic lymph nodes were 15 (range, 2-93) and 2 (range, 1-57) respectively. There was not statistically difference in baseline characteristics between the tumor location subgroups (Table 1).

\section{Survival Analysis}

The median follow-up period for all eligible patients was 63.34 (1.3-168.05) months. 64 (29.7\%) patients experienced tumor metastasis, 60 (27.9\%) patients died by cut-off date.

The median 3-year OS was $125.8( \pm 5.23)$ months for all patients. The median 3-year survival was $92.2( \pm 5.81)$ months for the RCC and $132.2( \pm 5.52)$ months for the LCC $(\mathrm{p}=0.037)$ groups. DFS and OS rates were $81 \%$ and $83 \%$ in all patients. The 3 -year DFS rate was $88 \%$ vs. $78 \%(\mathrm{p}=0.07)$ (Figure $1 \mathrm{~A})$, and 3 -year OS rate was $76 \%$ vs. $87 \%(\mathrm{p}=0.03$ ) (Figure 1B) for RCC and LCC patients respectively. In univariate analyses; age, $\mathrm{N}$ stage, TNM stage, risk group, venous invasion and tumor location affect survival, while multivariate analyses showed that TNM stage and venous invasion is effective on survival (Table 2). None of these variables affected DFS in univariate and multivariate analyses.

The total metastasis rate, liver metastasis and lung metastasis were not significiantly different between RCCs and LCCs (all p>0.050) (Table 3). Peritoneal carcinomatosis was more common in RCCs than LCCs $(23.4 \%$ vs. $15 \%, \mathrm{p}=0.038)$.

\section{Toxicities}

No significiant differences were identified for neutropenia, thrombocytopenia, neurotoxicity and nause and vomiting. Grade 3-4 neutropenia was $19.7 \%$ and $10.7 \%$, grade 3-4 thrombocytopenia was $5.2 \%$ and $5.0 \%$, grade $2-3$ nause and vomiting was $11.8 \%$ and $13.9 \%$ and grade $2-3$ neurotoxicity was $18.4 \%$ and $17.2 \%$ (grade 4 neurotoxicity not seen in any patient) for RCCs and LCCs ( $<<0.005$ for all) (Table 4).

\section{DISCUSSION}

Studies in the literature have discussed the demographic, biological, genetic, clinical and survival differences between left-sided and right-sided colon cancers. ${ }^{30-34}$ Bufill demonstrated two distinct genetic categories of colon cancers (left-sided and right-sided colons) for the first time in 19903 and various studies have been conducted based on this concept. ${ }^{35-39}$ However, it is still not clear whether the location of primary tumour is an independent factor in locoregional colon cancer. In a study by Wray et al. ${ }^{11}$ sigmoid colon cancers were found to have a lower tumour grade, an earlier stage, and an independent decreased CRC-specific mortality compared to proximal tumors. Huang et al. demonstrated that patients with right-sided colon cancer had significiantly worse overall and cancer specific survival rates compared to patients with left-sided colon cancer and the differences were significant only in patients with stage III CRC. ${ }^{12}$ Zhang et al. showed that both 5-year overall survival and recurrence-free survival were significantly different and survival gradually decreased for tumors from the cecum to the sigmoid colon in 895 stage III colon cancer patients treated with curative resection and subsequently received adjuvant chemotherapy with oxaliplatin. ${ }^{13}$ So far, the strongest evidence was 
International Journal of Hematology and Oncology

\begin{tabular}{|c|c|c|c|c|}
\hline Parameters & Overall cases (n, \%) & Left sided (n, \%) & Right sided ( $n, \%)$ & $\mathbf{p}$ \\
\hline Overall & $215(100)$ & $139(64.6)$ & $76(35.4)$ & \\
\hline \multicolumn{5}{|l|}{ Age (years) } \\
\hline$<65$ & $140(65)$ & $100(71.9)$ & $40(52.6)$ & 0.23 \\
\hline$\geq 65$ & 75 (34.8) & $39(28.1)$ & $36(47.4)$ & \\
\hline Gender & & & & 0.43 \\
\hline Male & $122(56.7)$ & $75(54)$ & $47(61.8)$ & \\
\hline Female & $92(43.3)$ & $64(46)$ & $29(38.2)$ & \\
\hline Tumor differantiation & & & & 0.92 \\
\hline Wel/modarate & $178(85.5)$ & $121(89.6)$ & $57(78.1)$ & \\
\hline Poor/undifferentiated & $30(14.4)$ & $14(10.4)$ & $16(21.9)$ & \\
\hline T stage & & & & 0.87 \\
\hline $\mathrm{T} 1-\mathrm{T} 2$ & $10(4.6)$ & $6(4.3)$ & $4(5.3)$ & \\
\hline T3 & $126(58.6)$ & $81(58.3)$ & $45(59.2)$ & \\
\hline $\mathrm{T} 4$ & $79(36.7)$ & $52(37.4)$ & $27(35.5)$ & \\
\hline \multicolumn{5}{|l|}{ N stage } \\
\hline $\mathrm{N} 1$ & $152(70.7)$ & $103(74.2)$ & $49(64.5)$ & \\
\hline N2 & 63 (29.3) & $36(25.8)$ & 27 (35.5) & \\
\hline TNM stage & & & & 0.67 \\
\hline $3 \mathrm{~A}$ & $9(4.2)$ & $5(3.6)$ & $4(5.3)$ & \\
\hline 3B & $161(74.8)$ & $108(77.7)$ & $53(69.7)$ & \\
\hline $3 \mathrm{C}$ & $45(21)$ & $26(18.7)$ & $19(25)$ & \\
\hline Risk stratification & & & & 0.77 \\
\hline Low risk & $103(48)$ & 69 (49.6) & $34(44.7)$ & \\
\hline High risk & $112(52)$ & $70(50.4)$ & $42(55.3)$ & \\
\hline Lymph node dissection & & & & 0.48 \\
\hline$\geq 12$ & $156(72.5)$ & $97(69.8)$ & $59(77.6)$ & \\
\hline$<12$ & $59(27.5)$ & $42(30.2)$ & $17(22.4)$ & \\
\hline Perineural invasion & & & & 0.53 \\
\hline Yes & $82(42)$ & $55(43.7)$ & 27 (39.1) & \\
\hline No & $113(58)$ & $71(56.3)$ & $42(60.9)$ & \\
\hline Lymphatic invasion & & & & 0.12 \\
\hline Yes & $133(68.9)$ & $80(64)$ & $53(77.9)$ & \\
\hline No & $60(31.1)$ & $45(36)$ & $15(22.1)$ & \\
\hline Venous invasion & & & & 0.23 \\
\hline Yes & $93(47.7)$ & $56(44)$ & $37(54.4)$ & \\
\hline No & 102 (52.3) & $71(66)$ & $31(45.6)$ & \\
\hline Adjuvant chemotherapy & & & & 0.92 \\
\hline Full & $109(50.7)$ & $70(50.3)$ & 39 (51.3) & \\
\hline Short & 106 (49.3) & $69(49.7)$ & $37(48.7)$ & \\
\hline Dose reduction & & & & 0.97 \\
\hline Yes & $80(41.7)$ & $53(42)$ & $27(41)$ & \\
\hline No & $112(58.3)$ & $73(58)$ & $39(59)$ & \\
\hline
\end{tabular}

reported in a meta-analysis of 66 studies including about 1.5 million patients with all stages of colon cancer. This meta-analyses demonstrated that LCCs are associated with a significiantly lower risk of mortality compared to RCCs (HR 0.82; 95\% CI: $0.79-0.84, \mathrm{p}<0.01)$ and this finding was independent of race, cancer stage and adjuvant chemothera- py. ${ }^{14}$ Similarly, Brungs et al. found improved overall and cancer specific survival rates RCC patients with stage I and II, but RCC patients with stage III had a worse overall survival and a trend to worse cancer specific survival. ${ }^{15}$ In their meta-analyses, RCC were more likely to have a more advanced grade, stage and more commonly occurred in older 
International Journal of Hematology and Oncology
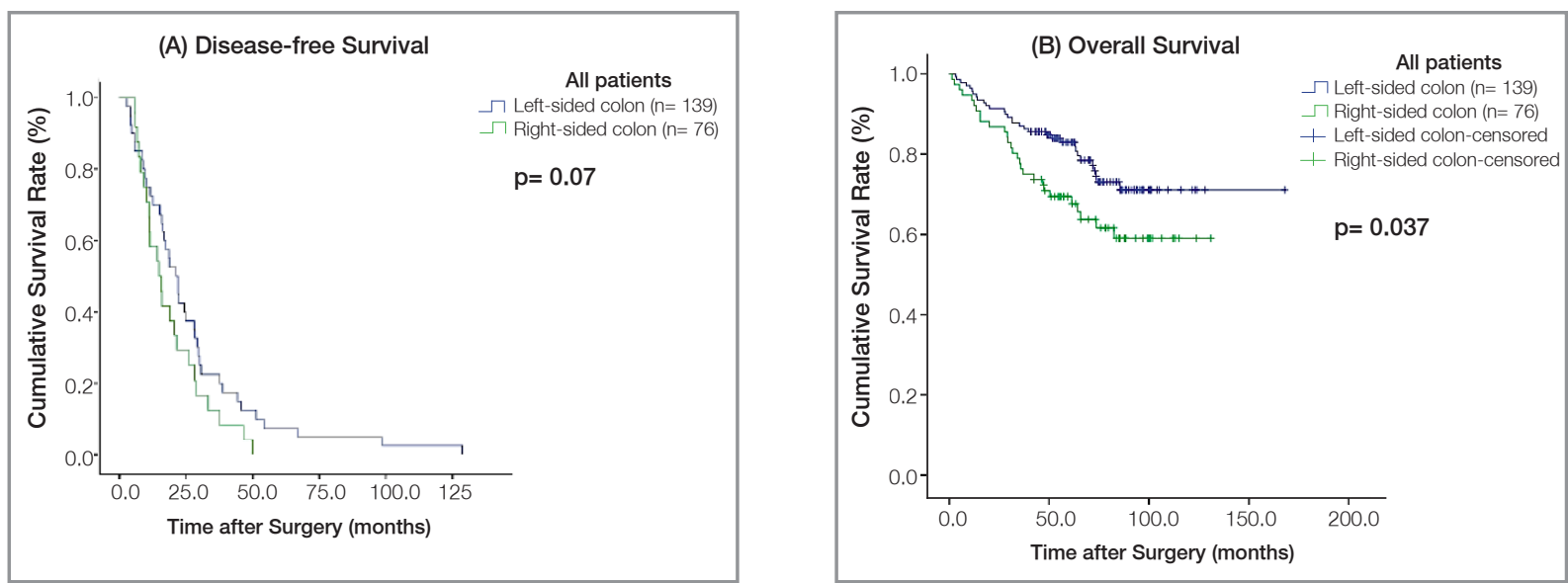

Figure 1. Kaplan-Meier curves of patients with stage III colon cancer grouped by right-and left-sided colon

A: Disease-free survival of all patients; B: Overall survival of all patients

patients with more comorbidities. In this study, we have demonstrated that TNM stage and venous invasion were independent poor prognostic factors for overall survival, but conversely tumor location was not. 3-year DFS rates were similar between the two groups; however, patients with RCC exhibited a worse 3-year overall survival than those with LCC. While the DFS rate was similar, the difference of overall survival suggests that the patients with right colon cancer are similar to the left colon in the early period, but they have an aggressive course when they progress to the metastatic stage. The incidence of peritoneal metastasis, which has been demonstrated as a risk factor resulting in the worst survival outcome, was significiantly higher in patients with RCC compared to those with LCC..$^{40}$ This may be one of the factors playing a role in short survival of patients with RCC.

Accumulating evidence has shown that the location of the primary tumor can be both a prognostic and predictive factor of response to EGFR inhibitors in metastatic colorectal cancers. ${ }^{41-46}$ Many studies have shown that panitumumab and cetuximab confer little if not any benefit to patients with meta-

\begin{tabular}{|c|c|c|c|c|}
\hline \multirow[t]{2}{*}{ Variables } & \multicolumn{2}{|c|}{ Univariate Analyses } & \multicolumn{2}{|c|}{ Multivariate Analyses } \\
\hline & HR & $\mathbf{p}$ & HR & $\mathbf{p}$ \\
\hline Age. years ( $\geq 65$ vs < 65) & $0.42(0.23-0.70)$ & 0.001 & $1.78(1.02-3.09)$ & 0.040 \\
\hline Gender ( Male vs. Female) & $1.41(0.62-1.73)$ & 0.860 & & \\
\hline Differention (Well vs Moderate vs Poor) & $2.16(1.16-4.03)$ & 0.015 & $0.56(0.29-1.08)$ & 0.088 \\
\hline Tstage ( T4 vs T1-3) & $1.49(0.89-2.47)$ & 0.124 & & \\
\hline Nstage( N2 vs N1) & $2.43(1.45-4.05)$ & 0.001 & $0.88(0.39-1.97)$ & 0.764 \\
\hline Number of resected lymph nodes (< 12 vs. $\geq 12$ ) & $0.92(0.52-1.64)$ & 0.801 & & \\
\hline Stage (3C vs $3 B$ vs $3 A)$ & $2.63(1.58-4.40)$ & $<0.001$ & $0.37(0.17-0.80)$ & 0.043 \\
\hline Risk stratification (Low vs. High) & $1.87(1.10-3.18)$ & 0.021 & $1.19(0.56-2.56)$ & 0.641 \\
\hline Perineural invasion (Yes vs. No) & $1.42(0.83-2.43)$ & 0.192 & & \\
\hline Lymphatic invasion (Yes vs.No) & $1.37(0.75-2.52)$ & 0.29 & & \\
\hline Venous invasion( Yes vs.No) & $2.60(1.48-4.57)$ & 0.001 & $0.41(0.23-0.74)$ & 0.003 \\
\hline Tumor location & $1.70(1.02-2.83)$ & 0.039 & $0.71(0.41-1.25)$ & 0.243 \\
\hline Adjuvant chemotherapy (Full vs Short) & $1.45(0.87-2.42)$ & 0.149 & & \\
\hline Dose reduction (Yes vs No) & $0.74(0.41-1.34)$ & 0.331 & & \\
\hline
\end{tabular}




\begin{tabular}{|c|c|c|c|c|}
\hline Metastatic Patterns & $\begin{array}{l}\text { Total } \\
\text { (n: } 215, \%)\end{array}$ & $\begin{array}{l}\text { Left-sided } \\
\text { (n: } 139, \% \text { ) }\end{array}$ & $\begin{array}{l}\text { Right sided } \\
\text { (n: } 76, \%)\end{array}$ & $\mathbf{p}$ \\
\hline \multicolumn{5}{|l|}{ Postoperative metastasis } \\
\hline Yes & $64(29.7)$ & $40(28.7)$ & $24(31.5)$ & 0.39 \\
\hline No & $151(70.3)$ & 99 (71.3) & $52(68.5)$ & \\
\hline \multicolumn{5}{|l|}{ Liver metastasis } \\
\hline Yes & $24(37.5)$ & $13(32.5)$ & $11(45.8)$ & 0.29 \\
\hline No & $40(62.5)$ & $27(67.5)$ & $13(54.2)$ & \\
\hline \multicolumn{5}{|l|}{ Lung metastasis } \\
\hline Yes & $12(18.75)$ & $8(20)$ & 4 (16.6) & 0.32 \\
\hline No & $52(81.25)$ & $32(80)$ & $20(83.4)$ & \\
\hline \multicolumn{5}{|c|}{ Peritoneal carcinomatosis } \\
\hline Yes & $15(23.4)$ & $6(15)$ & $9(37.5)$ & 0.03 \\
\hline No & 49 (76.6) & $34(85)$ & $15(62.5)$ & \\
\hline
\end{tabular}

static colorectal cancer, when the primary tumour originated from the right side..$^{41,42,44,46}$ However, the effect of tumor location on the selection of adjuvant chemotherapy is unclear. The different clinical and biological characteristics of LCC and RCC may contribute to different prognostic benefits obtained from adjuvant chemotherapy. Gervaz et al. proposed that tumor side should be considered in colon cancer before group stratification in future research on adjuvant chemotherapy. ${ }^{37}$ Regardless of tumor location, adjuvant chemotherapy with fluoropyrimidines and oxaliplatin is the standart treatment in stage III colon cancer. ${ }^{21,47,48}$ Although it has been shown that the duration of chemotherapy can be shortened in some subgroups of patients with opere stage III colon cancer, studies showing the effect of tumor location on adjuvant therapy are limited..$^{26,27}$ Grothey et al. demonstrated that 3 months adjuvant XELOX chemotherapy was sufficient in patients with low risk (T1-3, N2) opere stage III colon cancer. In high risk (T4, N2) patients, 6-months duration of therapy was superior to that for a 3-months duration, ${ }^{26}$ but tumor sideness was not examined in this study. Should the tumor side affect the decision of adjuvan therapy duration in stage III operated colon cancers? In this study, we aimed to examine whether the duration of adjuvant chemotherapy and chemotherapy dose density affects DFS and overall survival in LCCs and RCCs. Approximately half of the patients $(49.3 \%)$ could not complete treatment and dose was reduced in $41.7 \%$ of patients. It was observed that early discontinuation or dose reduction did not affect survival.

The limitations of this study can be listed as follows. First, this is a retrospective study and has a limited number of patients, there was not enough information about drug dose reductions and toxicities. Second, the short follow-up duration was insufficient to evaluate 5-year survival outcome. Finally, tumour molecular features such as MSI, BRAF and RAS mutations were not studied in the majority of patients, so could not be assessed. Thus these findings should be validated in further larger prospective studies.

\section{Conclusion}

Various studies have shown that RCC and LCC are considered as different tumor entities and RCC is more agressive than LCC. Tumor location is important in determining survival and choice of treatment in patients with stage IV colon cancer, but there are very limited studies evaluating the effect of tumor side on adjuvan chemotherapy in operated stage III colon cancer. Our findings suggest that prognostic features of patients with LCC and RCC were similar and the duration of treatment and dose intensity did not change survival of patients. Although 3-year DFS was similar, 3-year overal survival was longer in patients with LCC than those with RCC, suggest- 


\begin{tabular}{|c|c|c|c|}
\hline Toxicities & $\begin{array}{l}\text { Right-sided colon cancer } \\
\text { (n: } 76, \%)\end{array}$ & $\begin{array}{l}\text { Left-sided colon cancer } \\
\text { (n: } 139, \% \text { ) }\end{array}$ & $\mathbf{p}$ \\
\hline \multicolumn{4}{|l|}{ Neutropenia } \\
\hline Total & $35(46)$ & $63(45.3)$ & 0.932 \\
\hline Grade 1-2 & 20 (26.3) & $40(28.7)$ & 0.952 \\
\hline Grade 3-4 & $15(19.7)$ & 23 (16.6) & 0.778 \\
\hline \multicolumn{4}{|c|}{ Thrombocytopenia } \\
\hline Total & $23(30.2)$ & $40(28.7)$ & 0.812 \\
\hline Grade 1-2 & $19(25)$ & $33(23.7)$ & 0.765 \\
\hline Grade 3-4 & $4 \quad(5.2)$ & $7 \quad(5)$ & 0.963 \\
\hline \multicolumn{4}{|l|}{ Nause/vomiting } \\
\hline Total & $43(56.5)$ & $78(56.1)$ & 0.875 \\
\hline Grade 1-2 & $41(53.9)$ & $72(51.7)$ & 0.778 \\
\hline Grade 3-4 & $2(2.6)$ & $6 \quad(4.4)$ & 0.402 \\
\hline \multicolumn{4}{|l|}{ Neurotoxicity } \\
\hline Total & $31(40.7)$ & $57(41)$ & 0.819 \\
\hline Grade 1 & $18(23.6)$ & $32(23)$ & 0.781 \\
\hline Grade 2-3 & $13(17.1)$ & $25(17.9)$ & 0.892 \\
\hline \multicolumn{4}{|c|}{ Hand-foot syndrome } \\
\hline Total & $23(30.2)$ & 45 (32.3) & 0.429 \\
\hline Grade1 & 20 (26.3) & $36(25.8)$ & 0.342 \\
\hline Grade 2-3 & 3 (3.9) & $9(6.6)$ & 0.212 \\
\hline
\end{tabular}

ing that RCC has an aggressive course after progressing to the metastatic stage.

\section{REFERENCES}

1. Arnold M, Sierra MS, Laversenna M, et al. Global patterns and trends in colorectal cancer incidence and mortality. Gut 66: 683-691, 2017.

2. Argiles G, Tabernero J, Labianca R, et al. Localized colon cancer: ESMO Clinical Practice Guidlines for diagnosis, treatment and follow-up. Ann Oncol 31: 1291-1305, 2020.

3. Bufill JA. Colorectal cancer: evidence for distinct genetic categories based on proximal or distal tumor location. Ann Intern Med 113: 779-788, 1990.

4. Yamauchi M, Lochhead P, Morikawa T, et al. Colorectal cancer: a tale of two sides or a continuum? Gut 61: 794-797, 2012.

5. Wang F, Bai L, Liu TS, et al. Right-sided colon cancer and left-sided colorectal cancers respond differently to cetuximab. Chin J Cancer 10: 384-393, 2015.

6. Weiss J, Schumacher J, Allen GO, et al. Adjuvant chemotherapy for stage II right-sided and left-sided colon cancer: analysis of SEER-medicaredata. Ann Surg Oncol 21: 17811791,2014
7. Benedix F, Kube R, Meyer F, et al. Colon/Rectum Carcinomas (Primary Tumor) Study Group Comparison of 17,641 patients with right- and left-sided colon cancer: differences in epidemiology, perioperative course, histology, and survival. Dis Colon Rectum 53: 57-64, 2010.

8. Yamauchi M, Morikawa T, Kuchiba A, et al. Assessment of colorectal cancer molecular features along bowel subsites challenges the conception of distinct dichotomy of proximal versus distal colorectum. Gut 61:847-854, 2012.

9. Suttie SA, Shaikh I, Mullen R, et al. Outcome of right- and leftsided colonic and rectal cancer following surgical resection. Colorectal Dis 13:884-889, 2011.

10. Yahagi $\mathrm{M}$, Okabayashi $\mathrm{K}$, Hasegawa $\mathrm{H}$, et al. The worse prognosis of right-sided compared with left-sided colon cancers: a systematic review and meta-analysis. J Gastrointest Surg 20: 648-655, 2016.

11. Wray CM, Ziogas A, Hinojosa MW, et al. Tumor subsite location within the colon is prognostic for survival after colon cancer diagnosis. Dis Colon Rectum 52: 1359-1366, 2009.

12. Huang CW, Tsai HL, Huang MY, et al. Different clinicopathologic features and favorable outcomes of patients with stage III left-sided colon cancer. World J Surg Oncol 13: 257, 2015.

13. Zhang $Y, M a ~ J$, Zhang S, et al. A prognostic analysis of 895 cases of stage III colon cancer in different colon subsites. Int J Colorectal Dis 30: 1173-1183, 2015. 
14. Petrelli F, Tomesallo G, Borgonova K, et al. Prognostic Survival Associated With Left-Sided vs. Right-Sided Colon Cancer. A Systematic Review and Meta-analysis. JAMA Oncol 3: 211-219, 2017

15. Brungs D, Aghmesheh M, Souza P, et al. Sideness is prognostic in locoregional colon cancer: An analysis of 9509 Australian patients. BMC Cancer 17: 251-259, 2017.

16. André T, BoniC, Mounedji-BoudiafL, et al: Oxaliplatin, fluorouracil, and leucovorin as adjuvant treatment for colon cancer. N Engl J Med 350: 2343-2351, 2004.

17. André $\mathrm{T}$, Boni $\mathrm{C}$, Navarro $\mathrm{M}$, et al: Improved overall survival with oxaliplatin, fluorouracil, and leucovorin as adjuvant treatment in stage II or III colon cancer in the MOSAIC trial. J Clin Oncol 27: 3109-3116, 2009.

18. André T, de Gramont A, Vernerey D, et al: Adjuvant fluorouracil, leucovorin, and oxaliplatin in stage II to III colon cancer: Updated 10-year survival and outcomes according to BRAF mutation and mismatch repair status of the MOSAIC study. J Clin Oncol 33: 4176-4187, 2015.

19. Kuebler JP, Wieand HS, O'Connell MJ, et al: Oxaliplatin combined with weekly bolus fluorouracil and leucovorin as surgical adjuvant chemotherapy for stage II and III colon cancer: Results from NSABP C-07. J Clin Oncol 25: 2198-2204, 2017.

20. Yothers G, O'Connell MJ, Allegra CJ, et al: Oxaliplatin as adjuvant therapy for colon cancer: Updated results of NSABP C-07 trial, including survival and subset analyses. J Clin Oncol 29: 3768-3774, 2011.

21. Haller DG, Tabernero J, Maroun J, et al: Capecitabine plus oxaliplatin compared with fluorouracil and folinic acid as adjuvant therapy for stage III colon cancer. J Clin Oncol 29: 14651471, 2011.

22. Schmoll HJ, Tabernero J, Maroun J, et al: Capecitabine plus oxaliplatin compared with fluorouracil/folinic acid as adjuvant therapy for stage III colon cancer: Final results of the N016968 randomized controlled phase III trial. J Clin 33: 3733-3740, 2015.

23. Murphy CC, Harlan LC, Warren JL, Geiger AM. Race and insurance differences in the receipt of adjuvant chemotherapy among patients with stage III colon cancer. J Clin Oncol 33: 2530-2536, 2015

24. Stotz M, Pichler M, Absenger G, et al. The preoperative lymphocyte to monocyte ratio predicts clinical outcome in patients with stage III colon cancer. Br J Cancer 110: 435-440, 2014.

25. Van Erning FN, Creemers GJ, De Hingh $\mathbb{H}$, et al. Reduced risk of distant recurrence after adjuvant chemotherapy in patients with stage III colon cancer aged 75 years or older. Ann Oncol 24: 2839-2844, 2013.

26. Grothey A,Sobrero FA, Shields FA, et al. Duration of Adjuvant Chemotherapy for Stage III Colon Cancer. N Engl J Med 378: 1177-1188, 2018.
27. Peng J, Li C, Wang F, et al. Right- and left- sided stage IIIcolon cancer present different outcomes of oxaliplatin-based adjuvant chemotherapy after curative resection. Cancer Manag Res 10: 2095-2103, 2018.

28. American Joint Commision on Cancer (AJCC) 8th edition. http://www.nccn.org (version 1.2021-December 22,2020).

29. Compton CC, Fielding LP, Burgardt LJ, et al. Prognostic factors in colorectal cancer. Collage of American pathologists consensus statement. Arch Pathol Lab Med 124: 974-994, 2000.

30. Samowitz WS, Albertsen H, Herrick J, et al. Evaluation of a large, population based sample supports a CpG island methylator phenotype in colon cancer. Gastroenterology 129: 837-845, 2005

31. Nosho K, Irahara N, Shima K, et al. Comprehensive biostatistical analysis of $\mathrm{CpG}$ island methylator phenotype in colorectal cancer using a large population based sample. PLoS One 3(11): e3698, 2008.

32. Ogino S, Chan AT, Fuchs CS, Giovannucci E. Molecular pathological epidemiology of colorectal neoplasia: an emerging transdisciplinary and interdisciplinary field. Gut 60: 397411, 2011.

33. Jess P, Hansen IO, Gamborg M, Jess T. A nationwide Danish cohort study challenging the categorisation into right-sided and leftsided colon cancer. BMJ Open 3: e002608, 2013.

34. Kim HS. Site-specific colorectal cancer; how is it different? Korean J Gastroenterol 61: 63-70, 2013.

35. lacopetta B. Are there two sides to colorectal cancer? Int J Cancer 10: 403-408, 2002.

36. Pocard M, Salmon RJ, Muleris M, et al. Two colons-two cancers? Proximal or distal adenocarcinoma: arguments for a different carcinogenesis. Bull Cancer 82: 10-21, 1995.

37. Gervaz P, Bucher P, Morel P. Two colons-two cancers: paradigm shift and clinical implications. J Surg Oncol 88: 261266, 2004.

38. Meguid RA, Slidell MB, Wolfgang $\mathrm{CL}$, et al. Is there a difference in survival between right- versus leftsided colon cancers? Ann Surg Oncol 15: 2388-2394, 2008.

39. Shen $\mathrm{H}$, Huang J, Pei $\mathrm{H}$, et al. Comparative proteomic study for profiling differentially expressed proteins between Chinese left- and right-sided colon cancers. Cancer Sci 104: 135-141, 2013.

40. Franko J, Shi Q, Meyers JP, et al. Analysis and Research in Cancers of the Digestive System (ARCAD) Group. Prognosis of patients with peritoneal metastatic colorectal cancer given systemic therapy: An analysis of indivudual patient data from prospective randomised trials from the Analysis and Research in Cancers of the Digestive System (ARCAD) DATABASE. Lancet Oncol 17: 1709-1719, 2016.

41. Brule SY, Jonker DJ, Karapetis CS, et al. Location of CoIon Cancer (Right-Sided Versus Left-Sided) as a Prognostic Factor and a Predictor of Benefit From Cetuximab in NCIC CO.17. Eur J Cancer 51: 1405-1414, 2015. 
42. Moretto R, Cremolini C, Rossini D, et al. Location of Primary Tumor and Benefit From Anti-Epidermal Growth Factor Receptor Monoclonal Antibodies in Patients With RAS and BRAF Wild-Type Metastatic Colorectal Cancer. Oncologist 21: 988-994, 2016.

43. Loupakis F, Yang D, Yau L, et al. Primary Tumor Location as a Prognostic Factor in Metastatic Colorectal Cancer. J Natl Cancer Inst 107(3): dju427, 2015.

44. Arnold D, Lueza B, Douillard JY, et al. Prognostic and predictive value of primary tumour side in patients with RAS wildtype metastatic colorectal cancer treated with chemotherapy and EGFR directed antibodies in six randomized trials. Ann Oncol 28: 1713-1729, 2017.

45. Yahagi M, Okabayashi $\mathrm{K}$, Hasegawa $\mathrm{H}$, et al. The worse prognosis of right-sided compared with left-sided colon cancers: A systematic review and meta-analysis. J Gastrointest Surg 20: 648-655, 2016.

46. Venook PA, Niedzwiecki D, Innocenti F, et al. Impact of primary tumor location on overall survival and progression-free survival in patients with metastatic colorectal cancer: Analyses of CALGB/SWOG 8045 (Alliance) (abstract). ASCO meeting abstracts 34: 3504, 2016.

47. Kosmider S, Lipton L (2007) Adjuvant therapies for colorectal cancer. World J Gastroenterol 13: 3799-3805, 2017.

48. Sharif S, O‘Connell MJ, Yothers G, Lopa S, Wolmark N. FOLFOX and FLOX regimens for the adjuvant treatment of resected stage II and III colon cancer. Cancer Investig 26: 956-963, 2008

\section{Correspondence: \\ Dr. Semiha URVAY}

Acibadem Kayseri Hastanesi

Tibbi Onkoloji Bolumu

Mustafa Kemal Pasa Bulvari No: 1

38030 Melikgazi

KAYSERI / TURKEY

Tel: (+90-554) 1817500

(+90-352) 2073915

e-mail: s.elmaci@yahoo.com.tr

\section{ORCIDs:}

Semina Urvay

0000-0002-0181-3842

Hacer Demir 0000-0003-1235-9363

Ali Gokyer

Ilhan Hacibekiroglu

0000-0002-1653-6155

Ahmet Kucukarda

0000-0002-0333-7405

Emre Cakir

0000-0001-7399-2360

Ismail Beypinar 0000-0003-0411-8818

Necla Demir

0000-0002-0853-4096

Burak Civelek

0000-0003-1051-4032

$0000-0002-5627-599 x$

Ersin Ozaslan 